\title{
Reid on the priority of natural language ${ }^{*}$
}

JOHN TURRI

john.turri@gmail.com

Abstract: Thomas Reid distinguished between natural and artificial language and argued that natural language has a very specific sort of priority over artificial language. This paper critically interprets Reid's discussion, extracts a Reidian explanatory argument for the priority of natural language, and places Reid's thought in the broad tradition of Cartesian linguistics.

\section{Introduction}

Noam Chomsky's work on human language reignited a dormant tradition of studying language as a way of revealing something important about human nature (Chomsky 1957). Chomsky traces the roots of his approach back through Wilhelm von Humboldt and Rene Descartes (Chomsky 1966). This tradition - what Chomsky calls Cartesian linguistics - treats the creative human use of language as especially noteworthy, in two senses. On the one hand, the available evidence seems woefully inadequate to account for the linguistic competence humans acquire. On the other hand, humans

\footnotetext{
This is the penultimate version (2013-08-10) of a paper forthcoming in $\mathrm{Ca}$ nadian Journal of Philosophy. Please cite the final, published version if possible.
} 
routinely invent novel ways of expressing themselves, which other humans have little difficulty understanding, despite the novelty.

Thomas Reid fits comfortably into this tradition. Reid thought that language ought to be studied because doing so promises "to lay open some of the first principles of human nature" and in particular the human mind (Reid 1764: 51). One purpose of this paper is to demonstrate, through a careful analysis of Reid's central argument in this area, how naturally Reid fits into the Cartesian linguistic tradition. Another purpose is to identify the most plausible version of Reid's argument, which complements Chomsky's own important conclusions about human nature. Reid's discussion of human language, in particular his distinction between natural and artificial signs, also provides a model for his later discussion of human perception (e.g. Reid 1764: ch. 6.24, p. 190), and it would be fruitful to investigate how the conclusions drawn here might be extended to Reid's views on perception. But I will not attempt that task here. It's worth emphasizing at the outset that Reid's philosophy of language has received scant attention in the secondary literature,${ }^{1}$ and the central passages and argument I discuss at great length below have previously received no attention.

As an indication of this, consider that the index to The Cambridge Companion to Thomas Reid doesn't even contain an entry for 'language' (though it does have one for Reid's interest in botany!), and contains only a meagre entry for 'signs'. Compare that to the multiple entries for 'language' and extensive entry for 'signs' in The Cambridge Companion to Berkeley, and the extensive entry for 'language' in The Cambridge Companion to Locke's "Essay Concerning Human Understanding". Moreover, the Berkeley Companion dedicates an entire chapter to Berkeley's theory of signs, and the Locke Companion dedicates a chapter to Locke's philosophy of language. (But compare Jensen 1979 and Castagnetto 1992.) 
In what follows I critically interpret and evaluate a principal distinction and argument due to Reid. The distinction and argument occur in the following passage, from Chapter 4 of Reid's Inquiry into the Human Mind: ${ }^{2}$

By language I understand all those signs which mankind use in order to communicate to others their thoughts and intentions, their purposes and desires. And such signs may be conceived to be of two kinds: First, such as have no meaning, but what is affixed to them by compact or agreement among those who use them; these are artificial signs: Secondly, such as, previous to all compact or agreement, have a meaning which every man understands by the principles of his nature. Language, so far as it consists of artificial signs, may be called artificial; so far as it consists of natural signs, I call it natural.

Having premised these definitions, I think it is demonstrable, that if mankind had not a natural language, they could never have invented an artificial one by their reason and ingenuity. For all artificial language supposes some compact or agreement to affix a certain meaning to certain signs; therefore there must be compacts or agreements before the use of artificial signs; but there can be no compact or

2 Since Immerwahr 1978, some have accepted that Reid's views changed significantly between his early work in the Inquiry and his later work in the Essays. I reject this reading of Reid, but it isn't necessary to belabor the point here, because I am focused on Reid's interesting and neglected discussion in the Inquiry. 
agreement without signs, nor without language; and therefore there must be a natural language before any artificial language can be invented: Which was to be demonstrated. (Reid 1764: section 4.2, p. 51)

My subsequent discussion divides into three parts. Section 2 considers Reid's distinction between artificial and natural signs in the first quoted paragraph. Section 3 considers several ways of understanding the argument in the second quoted paragraph. Section 4 advances a different interpretation of Reid's discussion, and relates it to Chomsky's views on grammar.

\section{The distinction}

On Reid's view, human language is the set of signs humans use "in order to communicate to others their thoughts and intentions, their purposes and desires." Reid divides these signs, and by extension language, into two categories: natural and artificial. Artificial signs are defined as those signs which have no meaning except for "what is affixed to them by compact or agreement among those who use them." The English word 'star' is an example of an artificial sign. It refers to stars because we agree that it will. The "thumbs-up" sign in Western societies signals approval because we agree that it will. Natural signs are defined as those signs which, prior to any "compact or agreement, have a meaning which every man understands by the principles of his nature." Reid says natural signs come in three basic types: "modulations of the voice, gestures, and features." 
Pointing is a gesture naturally understood as calling our attention to the thing ostended. Raising one's voice while furrowing one's brow is naturally understood to signify anger.

Clearly this distinction between artificial and natural signs is mutually exclusive. That is, as defined, no sign can be both natural and artificial. Reid's discussion strongly suggests that the distinction is also jointly exhaustive. That is, we're led to believe that every sign, respectively, must be either natural or artificial. If Reid thought there were other categories, then he would have said so.

But it's doubtful that the distinction is jointly exhaustive. At least, we have no reason to suppose that all signs fall into one or the other category. The primary reason for this is that Reid defines a natural sign as one that every human naturally understands. But surely there might be signs whose meaning some, but not all, humans understand naturally. To use an example that Reid might have acknowledged, it is often said that identical twins have an uncanny ability to interpret one another. Perhaps this is due to experience, or perhaps it's a natural talent they have in virtue of their intimately intertwined origins. It's readily conceivable that such a pair is born with a natural ability to signal their moods and interpret one another, in virtue of their tone, gestures and features, in ways unique to them. (For example recall Poe's Fall of the House of Usher, where we're told that "sympathies of a scarcely intelligible nature had always existed between" the twins Roderick and Madeline Usher. Signs unintelligible to others are perfectly intelligible to the twins.) These signs used by such twins would be neither 
artificial nor natural, as per Reid's definitions. Neither would such signs violate the Wittgensteinian prohibition on private language, which pertains to language that is essentially private. Not only would the twins' use not be essentially private, it is trivially true that it doesn't even count as contingently private, since it's used in common by two people.

Setting aside examples that Reid himself might have considered, drawing on evolutionary theory, we might even expect there to be many partially distributed natural tendencies to express states of mind in specific ways. For example suppose that touching your ear while speaking was reliably associated with an especially sincere commitment to truth-telling. ${ }^{3}$ A genetic mutation, resulting in a disposition to both (a) touch your ear as an expression of such a commitment and (b) to interpret such behavior likewise in others, might confer an advantage on those with the mutation. Such a mutation would at first be unique, and then, with any luck, propagate throughout the population over time, though it might never be universally distributed. Such a sign would count as neither artificial nor natural, as per Reid's definitions, but surely it's a sign nonetheless.

Reid could respond in at least two ways. On the one hand, he might add a third category to accommodate the examples. On the other hand, he might revise the definition of 'natural sign', so as to include such signs as natural. Call this an inclusive definition of

3 Suppose this commitment to be well beyond the default commitment to truth-telling embodied in Reid's "principle of veracity." See Reid 1764: 6.24, p. 193-4. 
'natural sign'. An inclusive definition might go like this: natural signs have a meaning prior to any agreement among those who use them, which meaning those people understand by principles of their nature. This creates space for the sort of idiosyncratic or partially distributed natural signs featured in our examples. Perhaps the difference between these two responses doesn't amount to much. But I favor the inclusive response, for two reasons. First, the people in our examples - the twins in the one case, the mutants in the other - do express and understand the signs in question "by principles of their nature." That makes it natural to include them as "natural signs," and so I shall. Second, the inclusive definition seems best suited to Reid's argument, to which we now turn.

\section{The argument}

Here's the heart of the relevant passage again:

[I]t is demonstrable, that if mankind had not a natural language, they could never have invented an artificial one. All artificial language supposes some compact or agreement to affix a certain meaning to certain signs; therefore there must be compacts or agreements before the use of artificial signs; but there can be no compact or agreement without signs, nor without language; and therefore there must be a natural language before any artificial language can be invented: Which was to be demonstrated.

Reid speaks here of artificial and natural "language." This can be 
misleading, at least to modern ears, since we tend to associate "language" with robust communication systems, replete with syntactical and semantic rules, like French or Chinese. But as we saw earlier, by "language" Reid refers to all signs we use in order to communicate, not just the verbal signs associated with what we typically call a "language." So I will interpret his argument accordingly.

Something along roughly the following lines seems to be the most natural interpretation of Reid's argument.

1. Humans invented artificial signs. (Assumption)

2. The invention of artificial signs requires earlier agreement among those who invented them. (Premise)

3. There can be no agreement without the use of signs. (Premise)

4. So among themselves humans earlier used signs, whose meaning preceded the invention of artificial signs. (From 13)

5. Signs whose meaning precedes the use of artificial signs are natural signs. (Premise)

6. So among themselves humans earlier used natural signs. (From 4-5)

7. So if humans invented artificial signs, then among themselves they earlier used natural signs. (From 1-6)

Line 1 is an assumption for conditional proof, and so isn't subject to question. Lines 2 and 5 are supported by the definitions of 'artificial sign' and 'natural sign'. Line 3 is, I presume, supposed to be obvious. The inference to 6 is obviously valid, as is the inference to 7. By 
'use' I intend 'meaningful use', which should dispel any question about the validity of the inference to 4 .

Now we can see why I earlier claimed that the inclusive definition of 'natural sign' better suits Reid's argument. It's implausible that the invention of artificial signs among, say, a small group of people in South America requires these people to reach prior agreement by using signs that all humans naturally understand by principles of their nature. It suffices that the small group reaches prior agreement by using signs that they understand. It's simply irrelevant whether some other people in, say, central Asia, whom our South Americans never have and never will meet, would likewise understand those signs. Even supposing that the central Asians wouldn't understand, that doesn't prevent our South Americans from using the signs to agree among themselves.

Next I will present an objection to Reid's argument. This will be followed by a series of imagined replies, refinements and rebuttals. This process will enable a better appreciation of Reid's argument, and help us to decide whether Reid's conclusion, or something in the ballpark, is true.

We do not by a principle of our nature understand 'wolves' to refer to wolves. The word 'wolves' is not a sign in natural human language. And yet it certainly seems possible that a human, call him 'Wally', might decide to use 'wolves' in order to communicate to others his thought that wolves lurk nearby. This invention of this artificial sign didn't require prior agreement using natural signs. So premise 2 is false. 
"Oh, but it did require agreement," it might be replied. "Wally had to agree with himself to use 'wolves' to refer to wolves." In response, if we're to count such a decision as an agreement with oneself, then premise 3 is false. One doesn't communicate such a decision to oneself. One doesn't use signs in order to communicate such a decision to oneself. Neither does one need to use signs to make such a decision.

Perhaps it will instead be replied, "We should understand Reid's argument to pertain not merely to the invention of artificial signs, but the invention and use of them." This reply can be met by extending the example. Suppose Wally says 'wolves' to a Stranger he encounters along the forest trail one evening, in order to communicate to his thought that wolves lurk nearby. Nothing here requires prior agreement on the meaning of 'wolves' between Wally and the Stranger, or between Wally and anyone else.

Perhaps it will instead be replied, "We should understand the argument to pertain to the invention and effective interpersonal use of artificial signs. The Stranger will just be confused by Wally's utterance, so it doesn't count as an effective interpersonal use of artificial signs." This reply can be met by extending the example. Add that the Stranger hails from a community that, as it happens, uses the word 'wolves' to refer to wolves. So she isn't the least bit confused by Wally's utterance. She immediately takes him to mean precisely what he does mean. (Perhaps she falsely, but reasonably, takes Wally to be a member of her community, despite having never seen him before.) 
"But notice," it might be replied, "that your latest extension of the case requires that the Stranger's community previously agreed to use 'wolves' that way. So the example doesn't threaten a suitably modified version of Reid's argument. The invention and effective interpersonal use of artificial signs requires agreement among some people or other." Fair enough. This reply can be met by modifying the example as follows. Instead of hailing from a community that uses 'wolves' to refer to wolves, our Stranger, like Wally, made the individual decision to use 'wolves' to refer to wolves. She is absorbed in thought when Wally abruptly says 'wolves' to her. She immediately takes him to mean precisely what he does mean, and takes precautions against the potential danger lurking nearby. None of this requires prior agreement between Wally and the Stranger.

"But the Stranger has no good reason to expect that Wally refers to wolves when he says 'wolves'!" it might be objected. "She might unreasonably believe him to be referring to wolves, but she doesn't know that he's referring to wolves. This is no witting and effective interpersonal use of artificial language, which is what we should take Reid to be concerned with." This last objection gains some measure of credibility when we consider three things. In the first place, consider a later passage from the Inquiry where Reid recapitulates the argument already quoted:

It appears evident from what hath been said on the subject of language, That there are natural signs, as well as artificial; and particularly, That the thoughts, purposes, and dispositions of the mind, have their natural signs in the features of 
the face, the modulation of the voice, and the motion and attitude of the body: That without a natural knowledge of the connection between these signs, and the things signified by them, language could never have been invented and established among men: and . . . this connec-tion ... we may call the natural language of mankind. (1764: 5.3, p. 59)

Here Reid seems to characterize natural language in terms of knowing the connection between sign and signified. ${ }^{4}$ It stands to reason, then, that he'd characterize the effective interpersonal use of artificial language in terms of knowing the connection between sign and signified.

In the second place, careful inspection reveals that the conclusion Reid ultimately draws is stronger than what he initially says he would prove. Initially he says, "It is demonstrable, that if mankind had not a natural language, they could never have invented an artificial one by their reason and ingenuity." Call this the initial statement of Reid's thesis. But when presenting the actual argument, he concludes, "Therefore there must be a natural language before any artificial language can be invented: Which is what was to be demon-

4 There is a close affinity between what Reid calls "natural signs" and what Grice calls "natural meaning." To illustrate natural meaning, Grice used the example "those spots mean measles" (1957). To illustrate natural signs, Reid used examples such as "smoke is a natural sign of fire" and a certain countenance on a human face is "a natural sign of anger" (1764: 177). Reid's "natural language of mankind" might thus be regarded as a subset of Gricean natural meaning, where the signs in question are those features of human behavior and countenance that signify one's state of mind. But as I discuss in the main text, Reid might impose a further epistemic constraint on which natural signs are fit for inclusion in natural human language. 
strated." Call this the final statement of Reid's thesis. The final statement entails the initial statement, but not vice versa. (That is, the final statement is logically stronger.) If we cannot invent artificial language without an antecedent natural language, then we cannot by our reason and ingenuity - or, more generally, by any means whatsoever - invent artificial language without prior agreement via natural language. Perhaps Reid intended us to read the final statement of the thesis as implicitly qualified, in light of the initial statement.

In the third place, later in the same section, Reid says that we could not, by all our "wit and ingenuity" alone, invent artificial language without a prior natural language, apparently simply reiterating what he takes himself to have proven.

In light of these three considerations, it is at least plausible that Reid intended to conclude only that we cannot wittingly invent artificial language without prior agreement via natural language. To wittingly invent an artificial sign is to invent a sign, knowing what it signifies.

This is an interesting objection, which leads us in a potentially promising direction. But first notice that it doesn't fully deliver on what our critic initially promised. Even accepting the weaker interpretation of the argument, featuring the initial statement of Reid's thesis, we may not conclude that Reid was concerned with the witting and effective interpersonal use of artificial language. He literally speaks only of the invention - the witting invention, if you like - of artificial language. This thesis succumbs to our initial example, 
wherein Wally decides to use 'wolves' to refer to wolves. Surely there's no problem supposing that he wittingly does so. Indeed, this is the natural understanding of the case. It would be odd to suggest that despite consciously deciding to use 'wolves' that way, he nevertheless doesn't know that he does so. So even taking into account the emphasis on knowledge found elsewhere, we still must substantially depart from the letter of the text in order to focus on the witting and effective interpersonal use of artificial language.

But let's set aside, for the moment at least, any concern about literal fidelity to Reid's text. Having come this far, it's worth asking whether this Reidian thesis - I don't say Reid's thesis - is true. I suspect that even this thesis is false. To substantiate this suspicion, we must construct a new example, involving onomatopoeia.

We do not, by a principle of our nature, understand the cry 'owooo' to mean anything. The cry 'owooo' is not a sign in natural human language. And yet it certainly seems possible that a human with some experience with wolves, call him 'Howie', might decide to use the cry 'owooo' in order to communicate to others his thought that wolves lurk nearby. The invention of this artificial sign didn't require prior agreement using natural signs. And it seems quite natural that Howie would settle on this artificial sign for wolves, having learned that wolves uniquely cry 'owooo' in that distinctive sort of way, which anyone who has heard a wolf howl would recognize.

Suppose Howie is exiting the forest along the main path at dusk, having just escaped a ravenous wolf pack, when he notices a Stranger entering the forest. Howie knows that wolves lurk nearby, 
and howls 'owooo' at the Stranger, in order to communicate this thought. Moreover, Howie knows that any human adult around these parts knows what a wolf howl sounds like. So it stands to reason that the Stranger would interpret Howie as referring to wolves. And the Stranger interprets him precisely that way. This certainly seems to qualify as a witting and effective interpersonal use of artificial language. But it wasn't preceded by any agreement, using natural signs or otherwise, between Howie and the Stranger. ${ }^{5}$

Thus, in addition to concluding that Reid's original distinction requires improvement, that Reid's original argument fails, and that Reid's original thesis is false, I also conclude that the qualified Reidian thesis under consideration is false too. The invention of artificial signs does not strictly require prior agreement via natural language, and neither does the witting and effective interpersonal use of artificial signs.

\section{An explanatory hypothesis}

My critique of Reid relied on possible but highly peculiar cases, some involving coincidences that we couldn't reasonably expect to occur frequently. But if we want to account for the highly systematic

5 Earlier we noted a similarity between Reidian natural signs and Gricean natural meaning. The present example highlights a further similarity, this time in terms of Reidian "artificial signs" and Gricean "nonnatural meaning." Gricean nonnatural meaning can be glossed as follows: a speaker S's utterance $U$ means that $P$ because of S's intention that his audience infer, based on the fact that $S$ uttered $U$, that $S$ intends them to infer that $S$ believes that $\mathrm{P}$ (and perhaps also that $\mathrm{S}$ intends them to infer that $\mathrm{P}$ in part because S believes that P). See Grice 1957 and 1969. Howie has a Gricean reflexive communicative intention. 
and stable institution that is artificial human language, it seems unlikely that we'll be satisfied with an appeal to such coincidences, especially in the quantity that would be required from a thorough accounting. It is in the spirit of Reid's original discussion, then, that I offer the following hypothesis.

Artificial human languages are frequently invented. Inventing a systematic and stable language no doubt takes time and effort, but it isn't especially difficult - as Reid puts it, "there is no great ingenuity required" - for a group of humans to fairly quickly settle on a stable and extensible set of signs for the purposes of communicating among themselves. This is true even if they are complete strangers who initially don't share a single artificial sign in common. The best explanation for the relative ease with which such humans can invent an artificial language is that they share a natural language which they can readily implement to agree on meanings for artificial signs. For example, pointing to something and saying 'apple' in a clear, steady voice and then proceeding to do the same with several other objects that superficially resemble the first is an especially effective way to get a group of humans to understand that you're using 'apple' to refer to things of that kind.

We thus have a Reidian explanatory argument for the existence of a natural human language. This language seems an especially apt tool for establishing a common vocabulary. It thus complements Chomsky's explanatory argument for the existence of innate grammatical principles. On Chomsky's view, the best explanation of how easily human children learn the grammatical rules of artificial lan- 
guage is that we have innate knowledge of the most fundamental grammatical principles underlying all artificial human languages. Likewise on the Reidian view, the best explanation of how easily humans can invent, from scratch, a common vocabulary is that we share a natural tendency to interpret some gestures and expressions to signify certain things. Putting Chomsky and Reid together: the "original constitution of our minds" equips us with the tools for acquiring both the grammar and lexicon of artificial human languages.

Not only are artificial human languages easily invented, they are effortlessly maintained. This points to a further "original principle of the human constitution," namely, that there is "in the human mind an early anticipation, neither derived from experience, nor from reason, nor from any compact or promise, that our fellowcreatures will" continue using words and other signs in the same way they previously have (Reid 1764: ch. 6.24, p. 193). Thus we are led to posit a further fascinating feature of the human mind, if we are to account for the effortless stability of artificial human languages. ${ }^{6}$

\section{References}

Castagnetto, Susan. 1992. Reid's answer to abstract ideas. Journal of philosophical research 17: 39-60.

6 For helpful conversation and feedback, I thank Christian Hegele, Kevin Kuhl, Patrick Rysiew, and Nicholas Wolterstorff. Special thanks go to Angelo Turri. This research was supported by the Social Sciences and Humanities Research Council of Canada and an Ontario Early Researcher Award. 
Chomsky, Noam. 1957. Syntactic structures. The Hague: Mouton.

Chomsky, Noam. 1966. Cartesian linguistics: a chapter in the history of rationalist thought. New York: Harper \& Row.

Cuneo, Terrence, and Rene van Woudenberg, eds. 2004. The Cambridge companion to Thomas Reid. Cambridge: Cambridge University Press.

Grice, H. P. 1957. Meaning. The Philosophical Review 66.3: 377-388.

Grice, H.P. 1969. Utterer's meaning and intention. The Philosophical Review 78.2: 147-177.

Immerwahr, John. 1978. The development of Reid's realism. The Monist 61: 245-256.

Jensen, Henning. 1979. Reid and Wittgenstin on philosophy and language. Philosophical studies 36: 359-376.

Newman, Lex, ed. 2007. The Cambridge companion to Locke's "essay concerning human understanding”. Cambridge: Cambridge University Press.

Reid, Thomas. 1764 [1997]. An inquiry into the human mind on the principles of common sense. Ed. Derek R. Brookes. University Park, Penn.: Pennsylvania State University.

Winkler, Kenneth P., ed. 2005. The Cambridge companion to Berkeley. Cambridge: Cambridge University Press. 